\title{
MC4R variants rs12970134 and rs17782313 are associated with obese polycystic ovary syndrome patients in the Western region of Saudi Arabia
}

Asma A. Batarfi ${ }^{1}$, Najlaa Filimban², Osama S. Bajouh ${ }^{2,3}$, Ashraf Dallol ${ }^{2}$, Adeel G. Chaudhary ${ }^{2}$ and Sherin Bakhashab ${ }^{1,2^{*}}$ (D)

\begin{abstract}
Background: Polycystic ovary syndrome (PCOS) is a common endocrine disorder causing infertility in reproductiveage women. The cause of PCOS is not fully understood but it is thought to be influenced by environmental and genetic factors. Obesity is greatly related to PCOS and its reduction is one of the major aims in treating PCOS. Melanocortin 4 receptor (MC4R) gene polymorphisms were detected to be associated with different levels of obesity. Therefore, we aimed to determine the genotype and allele frequency of MC4R variants rs 12970134 (A/G) and rs17782313 (C/T) in PCOS and investigate their association with PCOS and its clinical variables.
\end{abstract}

Methods: A case-control study was conducted on 189 women, consisting of 95 PCOS cases and 94 controls. Genotyping was performed by real-time polymerase chain reaction (PCR) using TaqMan ${ }^{\text {TM }}$ Genotyping assays. Quantitative data were presented as (median \pm interquartile range (IQR) whereas qualitative data were presented as frequencies. The chi-squared test was used to observe the difference between SNPs within the study groups (PCOS and control subjects). Multinomial logistic regression was used to test the risk of obesity and development of PCOS considering $p<0.05$ is statistically significant.

Results: Rs12970134 and rs17782313 are significantly associated with body mass index (BMl, $\mathrm{kg} / \mathrm{m}^{2}, p<0.0001$ ) in PCOS women but not associated with PCOS itself. Risk alleles in our population are A in rs12970134 and C in rs17782313 that are associated with high BMI $\left(>30 \mathrm{~kg} / \mathrm{m}^{2}\right)$ in obese women with PCOS $(\mathrm{OR}=1.348, p=0.002$ and $\mathrm{OR}=1.364, p=$ 0.002 respectively) in the homozygous state. In addition, we found that the other genotypes for non-obese PCOS group, AG/GG for rs12970134 and CT/TT for rs 17782313, are associated with hirsutism, loss of hair, hyperandrogenism and antiMüllerian hormone in PCOS.

Conclusions: These findings demonstrate that MC4R single nucleotide polymorphisms, rs12970134 and rs17782313, are correlated with elevated BMI in PCOS but are not causative factors for PCOS among women in the western region of Saudi Arabia. Moreover, the reverse genotypes are associated with major clinical variants in non-obese $\left(<30 \mathrm{~kg} / \mathrm{m}^{2}\right)$ PCOS patients may demonstrate a poor prognosis for this group.

Keywords: BMI, Polycystic ovary syndrome, MC4R, SNP

* Correspondence: sbakhashab@kau.edu.sa

${ }^{1}$ Biochemistry Department, King Abdulaziz University, P.O. Box 80218,

Abdullah Sulayman St., Jeddah 21589, Saudi Arabia

${ }^{2}$ Centre of Innovation in Personalized Medicine, King Abdulaziz University,

P.O. Box 80216, Jeddah, Saudi Arabia

Full list of author information is available at the end of the article

(c) The Author(s). 2019 Open Access This article is distributed under the terms of the Creative Commons Attribution 4.0 International License (http://creativecommons.org/licenses/by/4.0/) which permits unrestricted use, distribution, and reproduction in any medium, provided you give appropriate credit to the original author(s) and the source, provide a link to the Creative Commons license, and indicate if changes were made. The Creative Commons Public Domain Dedication waiver (http://creativecommons.org/publicdomain/zero/1.0/) applies to the data made available in this article, unless otherwise stated. 


\section{Background}

Polycystic ovary syndrome (PCOS) is a common heterogeneous endocrine disorder with prevalence up to $15-20 \%$ in reproductive-age women worldwide depending on which criteria are used [1]. The aetiology of PCOS is still unclear, but it is thought to be associated with environmental factors such as lifestyle and genetic factors $[2,3]$. There are three major criteria for PCOS diagnosis: one criterion raised by the National Institutes of Health $(\mathrm{NIH})$ which includes only the existence of hyperandrogenism (HA) and oligo/anovulation (OA), the second criterion was introduced by Androgen Excess Society (AES) which defined PCOS as HA with ovarian dysfunction or polycystic ovaries, and the Rotterdam criterion, which is widely used for PCOS diagnosis [4-6]. However, in the Rotterdam criterion, PCOS is diagnosed by the appearance of two out of three clinical features: OA, clinical or biochemical HA and polycystic ovarian morphology (PCOM) [7]. PCOM is characterized by the presence of 12 or more follicles in either ovary measuring $2-9 \mathrm{~mm}$ in diameter [8]. Furthermore, PCOS patients have an abnormal luteinizing hormone (LH) to follicle stimulating hormone (FSH) ratio [7]. Serum antiMüllerian hormone (AMH) also has been used as a marker for the ovarian antral follicle number and thus offers a diagnostic tool for PCOS, especially when accurate ultrasonic data are not available [9]. PCOS is related to endocrinemetabolic disorders, thus women with this syndrome are at high risk of dyslipidaemia, cardiovascular disease, insulin resistance, glucose intolerance, type 2 diabetes mellitus [10], and obesity [11]. Obesity is associated with PCOS, but its causal role has not yet been determined [11], although other explanations involve opposite causality, that is, PCOS raises susceptibility to weight gain [12]. The prevalence of obesity among PCOS patients in Saudi Arabia is 51\% as reported previously by Al-Ruhaily et al. [13]. Moreover, 50 to $80 \%$ of women with PCOS in other countries are obese $[14,15]$. Obesity increases the severity of PCOS and may play a central role in the development of HA and chronic anovulation [16]. There is an association of insulin resistance with PCOS but the molecular mechanisms of insulin resistance in PCOS vary from other insulin-resistance disorders such as obesity and diabetes [11, 17]. PCOS is a common, complex genetic disorder with multifactorial aetiology, in which a variety of genes interact with environmental factors to cause the disease [18]. The hereditary basis of PCOS increases the risk of the prevalence of PCOS among family women [10]. Recent genome-wide association studies (GWAS) have identified the susceptibility loci for many complex genetic diseases, diabetes and obesity [19-23]. These GWAS studies have detected variations in or near different genes, among them fat mass- and obesity-associated gene alpha-ketoglutarate dependent dioxygenase and melanocortin 4 receptor $(M C 4 R)$ in obesity [19, 21-23]. MC4R is located on chromosome
$18 q 22$, and it is the most common genetic cause for inherited morbid obesity [10, 24]. In addition, it is an important regulator in central melanocortin neuronal pathways [25]. Previous studies demonstrated several MC4R variants and common genetic polymorphisms near the $M C 4 R$ gene contributing to common obesity [22, 26, 27]. Among these variants, rs12970134 (A/G) and rs17782313 $(\mathrm{C} / \mathrm{T})$ have been studied most often. The majority of studies showed a significant association of these variants with obesity-related traits, whereas some studies revealed nonsignificant association [28-31]. Moreover, the association of rs12970134 MC4R variant with insulin resistance has been documented [26].

To our knowledge, no previous study has been conducted on the effect of MC4R polymorphism on PCOS among the Saudi population. Thus, in this study we aimed to determine the association between MC4R gene variants (rs12970134 and rs17782313) because these are risk factors in obesity; and different clinical characteristics of PCOS. This will aid in understanding the susceptibility of genetic variations in PCOS and their correlation to obesity. Therefore, we will be able to identify specific risk variants for PCOS and a better understanding of the genetic preposition for this disorder.

\section{Methods \\ Study design}

This is a case-control, observational and randomised study that was conducted from the Obstetrics and Gynaecology Clinics, King Abdulaziz University Hospital and the Centre of Innovation in Personalized Medicine (CIPM), KAU, Jeddah, Saudi Arabia, clinical database from 2016 up to 2018. The total population was 400 cases after applying the exclusion criteria. The exclusion criteria were as follows:

1. A condition with reproductive symptoms similar to PCOS, including congenital adrenal hyperplasia, Cushing syndrome, hyperprolactinemia, thyroid disease, and androgen-secreting tumours.

2. Chronic diseases, including diabetes, cardiovascular disease.

3. Any other female infertility factor.

The sample size was calculated using raosoft (www. raosoft.com) which indicated 196 women of reproductive age between 18 and 38 years old. The study was approved by the Biomedical Ethics Unit, Faculty of Medicine, KAU (approval number: 407-15) and written informed consent was obtained from participants prior to sample collection. The study was conducted in accordance with the Declaration of Helsinki.

The case group was 98 PCOS selected patients, diagnosed according to the Rotterdam Criteria Consensus 
and the control group was 98 women with normal ovulation. In days 2-4 of the menstrual cycle transvaginal or abdominal ultrasound was performed using a SonixTouch machine (Ultrasonix Medical Corporation, Richmond, BC, Canada) and serum hormonal levels for LH and FSH were measured with an automated multi-analysis system using electrochemiluminescence immunoassay (ECLIA) kits (Roche, Basel, Switzerland). Serum AMH levels were determined using an enzyme-linked immunosorbent assay using Ultra-Sensitive Anti-Müllerian hormone/Müllerian inhibiting substance (US AMH/MIS) kit (AnshLabs, Webster, TX, USA) according to the manufacturer's instructions. PCOM was confirmed by the presence of at least 12 follicles measuring between 2 and $9 \mathrm{~mm}$ in diameter in one ovary. Body mass index (BMI) was determined by a person's weight in kilograms over square of height in $\mathrm{m}^{2}$. HA was defined by the presence of hirsutism, acne or androgenic alopecia [32, 33]. Samples with poor quality were excluded from the statistical analysis to achieve 95 cases and 94 controls.

\section{Genotyping}

Genomic DNA was isolated from peripheral whole blood using the QIAamp DNA Mini Blood Kit (Qiagen, Hilden, Germany) according to the manufacturer's instructions. Genotyping of the MC4R variants rs12970134 (assay ID: C_3058722_10) and rs17782313 (assay ID: C_ 32667060_10) was performed using TaqMan $^{\text {Ti }}$ single nucleotide polymorphism (SNP) Genotyping Assays (Thermo Fisher Scientific, Waltham, MA, USA). Allelic PCR products were analysed using QuantStudio $12 \mathrm{~K}$ Flex Real-Time PCR System (Thermo Fisher Scientific).

\section{Statistical analysis}

A normality test was performed to show that the data do not follow the normal distribution. Quantitative data are presented as (median \pm interquartile range (IQR)), $p$-values were calculated using the Mann-Whitney test for non-normal distribution data, whereas qualitative data are presented as frequencies. Genotypes and allelic frequencies were calculated within our cohort population to determine the significant differences between PCOS and control groups. The chi-squared test was used to observe the difference between SNPs within the study groups (PCOS and control subjects). Differences between SNPs and continuous variables were tested using the Kruskal-Wallis test, the $p$-value was adjusted using the Bonferroni correction between pairwise comparisons. Further, multinomial logistic regression was used to determine the risk of high BMI and development of PCOS. The correlation of MC4R variants with PCOS symptoms was calculated using binary logistic regression for patients with regard to the control. $p<0.05$ was considered statistically significant. Data analysis was conducted using the IBM SPSS software version 24 (SPSS $^{\text {max }}$ Inc., Armonk, NY, USA).

\section{Results}

The clinical characteristics of the participants are summarized in Table 1.

\section{Allele and genotype frequency}

The distribution of rs12970134 and rs17782313 genotype and allele frequencies is listed in Table 2. MC4R rs12970134 genotypes (AA, AG and GG) frequencies were estimated for the PCOS group as 6.3, 40.0 and 53.7\%, respectively, whereas for the control group as 5.3, 37.2 and $57.4 \%$, respectively. Allele A and G frequencies for the same variant were estimated as 26.3 and $73.7 \%$, respectively for the PCOS group and 23.9 and $76.1 \%$, respectively, for the control group. However, MC4R rs17782313 genotypes (CC, CT and TT) frequencies were calculated for the PCOS group as 7.4, 40.1 and $51.6 \%$, respectively, whereas for the control group as 4.3, 36.2 and 59.6\%, respectively. Moreover, allele $\mathrm{C}$ and $\mathrm{T}$ frequencies were estimated as 27.9 and $72.1 \%$, respectively, for the PCOS group and 22.3 and $77.7 \%$, respectively, for the control group.

\section{The association of MC4R variants rs 12970134 and rs17782313 with PCOS}

There is no direct association between the MC4R SNPs and PCOS, in addition to the other clinical variables such as acne, hirsutism, loss of hair, HA, PCOM and OA by using the chi-squared test. There was significant difference between BMI $\left(>30 \mathrm{~kg} / \mathrm{m}^{2}\right)$ and $M C 4 R$ variants rs 12970134 and rs17782313 only in the patients' group $(p=0.003$ and $p=0.001$, respectively) as shown in Table 3 . In rs12970134, significant variance was detected by comparing $\mathrm{A} / \mathrm{A}$ to $\mathrm{A} /$ $\mathrm{G}$ and $\mathrm{A} / \mathrm{A}$ to $\mathrm{G} / \mathrm{G}$, whereas in rs17782313 significant differences were observed between $\mathrm{C} / \mathrm{C}$ compared with $\mathrm{C} / \mathrm{T}$ and $\mathrm{C} / \mathrm{C}$ compared to $\mathrm{T} / \mathrm{T}$.

Table 1 Clinical characteristics of PCOS patients and control subjects

\begin{tabular}{llll}
\hline Variable & Control $(n=94)$ & PCOS patients $(n=95)$ & $p$-value \\
\hline Age (years) & $21.0 \pm 3$ & $22.0 \pm 9.0$ & $0.015^{*}$ \\
BMI $\left(\mathrm{kg} / \mathrm{m}^{2}\right)$ & $22.7 \pm 5.9$ & $24.56 \pm 7.34$ & $0.003^{* *}$ \\
$\mathrm{LH}(\mathrm{IU} / \mathrm{ml})$ & $5.7 \pm 5.7$ & $9.0 \pm 8.7$ & $0.001^{* *}$ \\
FSH $(\mathrm{IU} / \mathrm{ml})$ & $4.6 \pm 2.6$ & $4.8 \pm 2.4$ & 0.339 \\
LH/FSH ratio & $1.2 \pm 1.5$ & $1.9 \pm 1.6$ & $0.001^{* *}$ \\
AMH $(\mathrm{ng} / \mathrm{ml})$ & $2.3 \pm 1.4$ & $4.8 \pm 4.76$ & $<0.0001^{* * *}$ \\
\hline
\end{tabular}

Values are expressed as median $\pm \mathrm{IQR}, p$-values were calculated using the Mann-Whitney test for non-normal distribution data. $p$-value $<0.05$ is statistically significant. $B M I$ body mass index, $L H$ luteinizing hormone, $F S H$ follicle stimulating hormone, $A M H$ anti-Müllerian hormone. ${ }^{*} p<0.05$, ${ }^{* *} p<0.01$, *** $p<0.001$ 
Table 2 Genotype and allele frequencies for MC4R variants rs12970134 and rs17782313

\begin{tabular}{|c|c|c|c|c|c|c|c|c|}
\hline$\overline{S N P}$ & rs12970134 & & & $p$-value & rs17782313 & & & $p$-value \\
\hline Genotype frequency & $\mathrm{AA}$ & $A G$ & GG & & CC & $C T$ & $\pi$ & \\
\hline Patient $(n=95)$ & $6(6.3 \%)$ & 38 (40.0\%) & $51(53.7 \%)$ & 0.86 & $7(7.4 \%)$ & 39 (40.1\%) & 49 (51.6\%) & 0.44 \\
\hline Control $(n=94)$ & $5(5.3 \%)$ & 35 (37.2\%) & $54(57.4 \%)$ & & $4(4.3 \%)$ & $34(36.2 \%)$ & $56(59.6 \%)$ & \\
\hline Total = 189 & $11(5.8 \%)$ & $73(55.6 \%)$ & 105 (38.6\%) & & $11(5.8 \%)$ & 73 (55.6\%) & $105(38.6 \%)$ & \\
\hline Allele frequency & A & G & & & C & T & & \\
\hline $\operatorname{PCOS}(n=95)$ & $50(26.3 \%)$ & $140(73.7 \%)$ & & & $53(27.9 \%)$ & 137 (72.1\%) & & \\
\hline Control $(n=94)$ & $45(23.9 \%)$ & $143(76.1 \%)$ & & & $42(22.3 \%)$ & $146(77.7 \%)$ & & \\
\hline
\end{tabular}

$p$-value was calculated using the chi-squared test

Furthermore, patients with A/A genotype are more likely to have high BMI $(\mathrm{OR}=1.348, p=0.002)$ than patients with G/G genotype in the rs12970134 variant using a multinomial logistic regression test. This indicates that A could be a risk allele of high BMI in PCOS women, whilst, in rs17782313 the test indicated that patients with the $\mathrm{C} / \mathrm{C}$ genotype are more likely to have higher BMI $(\mathrm{OR}=1.364, p=0.002)$ than patients with the $\mathrm{T} / \mathrm{T}$ genotype. This means that the effect of $\mathrm{C}$ allele on BMI should be in the homozygous state among women with PCOS (Table 4). No significant correlation with other study variables was detected in the PCOS group.

Moreover, the association of $M C 4 R$ variants rs 12970134 and rs17782313 with PCOS variables acne, loss of hair, hirsutism, PCOM, OA, BMI, HA, AMH, LH, FSH and LH/FSH ratio was studied using binary logistic regression. The analysis revealed a significant association between rs12970134 and hirsutism, loss of hair, HA and AMH but with the reverse genotype that is associated with high BMI. Patients with $A / G$ and $G / G$ genotypes are more likely to have loss of hair, hirsutism, HA and AMH than the control group with A/G and G/G genotypes as summarized in Table 5. Therefore, in rs12970134 variant, allele $\mathrm{G}$ is a risk allele that is associated with hirsutism, loss of hair, HA and high AMH level and only one allele is enough to manifest these symptoms. In addition, there is a significant association between rs17782313 and hirsutism, loss of hair, HA and AMH. Patients with C/T and T/ $\mathrm{T}$ genotypes are more likely to have hirsutism, loss of hair, hirsutism, HA and AMH than the control group with the same genotypes (Table 5). Hence, $\mathrm{T}$ allele in rs17782313 is potentially a risk allele associated with hirsutism, loss of hair, HA and high AMH level in PCOS patients and only one allele is enough to produce these symptoms.

Table 3 Association between MC4R variants rs12970134 and rs17782313 and the multiple variables

\begin{tabular}{|c|c|c|c|c|c|c|c|c|}
\hline \multicolumn{9}{|l|}{ rs12970134 } \\
\hline \multirow[t]{2}{*}{ Variables } & \multicolumn{3}{|c|}{ Patient $(n=95)$} & $p$-value & \multicolumn{3}{|c|}{ Control $(n=94)$} & $p$-value \\
\hline & $\mathrm{A} / \mathrm{A}$ & $\mathrm{A} / \mathrm{G}$ & $\mathrm{G} / \mathrm{G}$ & & $\mathrm{A} / \mathrm{A}$ & $\mathrm{A} / \mathrm{G}$ & $\mathrm{G} / \mathrm{G}$ & \\
\hline $\mathrm{BMI}\left(\mathrm{kg} / \mathrm{m}^{2}\right)$ & $33.5 \pm 9.4$ & $24.5 \pm 6.8$ & $23.5 \pm 6.6$ & $0.003^{* *}$ & $23.2 \pm 13.8$ & $21.1 \pm 5.5$ & $23.1 \pm 7.3$ & 0.941 \\
\hline $\mathrm{AMH}(\mathrm{ng} / \mathrm{ml})$ & $5.6 \pm 5.6$ & $4.9 \pm 5.5$ & $4.7 \pm 4.4$ & 0.953 & $2.2 \pm 0.0$ & $2.3 \pm 1.9$ & $2.3 \pm 1.4$ & 0.482 \\
\hline $\mathrm{LH}(\mathrm{IU} / \mathrm{ml})$ & $9.4 \pm 3.4$ & $8.8 \pm 8.9$ & $8.3 \pm 9.6$ & 0.941 & $3.4 \pm 5.7$ & $6.6 \pm 6.2$ & $5.6 \pm 5.3$ & 0.224 \\
\hline FSH (IU/ml) & $4.6 \pm 2.7$ & $5.3 \pm 2.9$ & $4.7 \pm 2.2$ & 0.300 & $3.3 \pm 4.3$ & $4.6 \pm 2.5$ & $4.9 \pm 2.6$ & 0.502 \\
\hline LH/FSH ratio & $2.1 \pm 1.3$ & $2.0 \pm 1.6$ & $1.7 \pm 1.7$ & 0.926 & $0.8 \pm 1.1$ & $1.7 \pm 1.4$ & $1.2 \pm 1.3$ & 0.325 \\
\hline \multicolumn{9}{|l|}{ rs17782313 } \\
\hline \multirow[t]{2}{*}{ Variables } & \multicolumn{3}{|c|}{ Patient $(n=95)$} & $p$-value & \multicolumn{3}{|c|}{ Control $(n=94)$} & $p$-value \\
\hline & $\mathrm{C} / \mathrm{C}$ & $\mathrm{C} / \mathrm{T}$ & $\mathrm{T} / \mathrm{T}$ & & $\mathrm{C} / \mathrm{C}$ & $\mathrm{C} / \mathrm{T}$ & $\mathrm{T} / \mathrm{T}$ & \\
\hline BMI $\left(\mathrm{kg} / \mathrm{m}^{2}\right)$ & $34.9 \pm 6.0$ & $24.1 \pm 5.6$ & $23.5 \pm 7.1$ & $0.001^{* * *}$ & $23.6 \pm 17.3$ & $21.4 \pm 7.0$ & $23 \pm 5.8$ & 0.794 \\
\hline $\mathrm{AMH}(\mathrm{ng} / \mathrm{ml})$ & $4.3 \pm 5.0$ & $4.9 \pm 5.5$ & $4.7 \pm 4.5$ & 0.982 & $2.3 \pm 0.0$ & $2.3 \pm 1.9$ & $2.3 \pm 1.6$ & 0.881 \\
\hline LH (IU/ml) & $9.3 \pm 6.1$ & $8.8 \pm 9.2$ & $8.4 \pm 9.6$ & 0.975 & $4.4 \pm 5.9$ & $6.1 \pm 6.4$ & $5.6 \pm 5.7$ & 0.573 \\
\hline $\mathrm{FSH}(\mathrm{IU} / \mathrm{ml})$ & $4.6 \pm 2.4$ & $5.2 \pm 2.7$ & $4.8 \pm 2.3$ & 0.690 & $3.8 \pm 4.8$ & $4.5 \pm 2.8$ & $4.9 \pm 2.3$ & 0.573 \\
\hline LH/FSH ratio & $1.8 \pm 1.6$ & $2.2 \pm 1.8$ & $1.7 \pm 1.6$ & 0.998 & $1.0 \pm 1.3$ & $1.7 \pm 1.4$ & $1.1 \pm 1.4$ & 0.367 \\
\hline
\end{tabular}

Quantitative data are presented as median \pm IQR. Kruskal-Wallis was applied and the $p$-value was adjusted by Bonferroni correction between pairwise comparisons. $A M H$ anti-Müllerian hormone, $B M I$ body mass index, FSH follicle stimulating hormone, $L H$ luteinizing hormone. ${ }^{* *} p<0.01,{ }^{* * *} p<0.001$ 
Table 4 Impact of MC4R variants rs12970134 and rs17782313 on PCOS using a multinomial logistic regression test

\begin{tabular}{|c|c|c|c|c|c|c|}
\hline SNP & Variable & Group & Genotype & $B$ & $p$-value & OR $(95 \% \mathrm{Cl})$ \\
\hline \multirow[t]{4}{*}{ rs12970134 ${ }^{a}$} & BMI $\left(\mathrm{kg} / \mathrm{m}^{2}\right)$ & Control $(n=94)$ & $A / G$ & -0.003 & 0.935 & $0.997(0.921-1.078$ \\
\hline & & & $A / A$ & 0.052 & 0.48 & $1.053(0.912-1.216)$ \\
\hline & & Patient $(n=95)$ & $A / G$ & 0.027 & 0.553 & $1.027(0.94-1.122)$ \\
\hline & & & $A / A$ & 0.298 & $0.002^{* *}$ & $1.348(1.113-1.631)$ \\
\hline \multirow[t]{4}{*}{ rs $17782313^{b}$} & BMI $\left(\mathrm{kg} / \mathrm{m}^{2}\right)$ & Control $(n=94)$ & $\mathrm{C} / \mathrm{T}$ & 0.035 & 0.935 & $1.035(0.957-1.12)$ \\
\hline & & & $\mathrm{C} / \mathrm{C}$ & 0.102 & 0.48 & $1.108(0.953-1.287)$ \\
\hline & & Patient $(n=95)$ & $\mathrm{C} / \mathrm{T}$ & -0.008 & 0.553 & $0.992(0.906-1.086)$ \\
\hline & & & $\mathrm{C} / \mathrm{C}$ & 0.311 & $0.002^{* *}$ & $1.364(1.121-1.661)$ \\
\hline
\end{tabular}

${ }^{a}$ The reference category is $\mathrm{G} / \mathrm{G}$

${ }^{\mathrm{b}}$ The reference category is $\mathrm{T} / \mathrm{T}$

${ }^{* *} p<0.01$

\section{Discussion}

In this study, we examined MC4R variants' (rs12970134 and rs17782313) contribution to obesity and their influence on the susceptibility to PCOS. We detected a highly significant association between both SNPs and high BMI in PCOS patients in Saudi Arabia. However, there was no direct association between those MC4R SNPs and PCOS. This is in concordance with previous studies among PCOS women, they have perceived that there is an association between MC4R SNPs (rs12970134 and rs17782313) and obesity whereas the SNPs are not risk factors for PCOS [34, 35]. Alternatively, a German study

Table 5 The correlation of MC4R variants rs12970134 and rs17782313 with PCOS symptoms using binary logistic regression for patients with regard to controls

\begin{tabular}{|c|c|c|c|c|c|}
\hline SNP & Variable & Genotype & B & $p$-value & OR $(95 \% \mathrm{Cl})$ \\
\hline \multirow[t]{12}{*}{ rs12970134 } & hirsutism & $\mathrm{A} / \mathrm{A}$ & 22.119 & 0.999 & \\
\hline & & $A / G$ & 1.713 & $0.014^{*}$ & $5.547(1.424-21.612)$ \\
\hline & & $\mathrm{G} / \mathrm{G}$ & 3.883 & $<0.0001^{* * *}$ & $48.583(6.185-381.647)$ \\
\hline & loss of hair & $\mathrm{A} / \mathrm{A}$ & 2.773 & 0.08 & $16(0.722-354.803)$ \\
\hline & & $A / G$ & 1.787 & $0.001^{* *}$ & $5.971(2.013-17.705)$ \\
\hline & & $\mathrm{G} / \mathrm{G}$ & 1.13 & $0.014^{* *}$ & $3.096(1.255-7.641)$ \\
\hline & $\mathrm{HA}$ & $\mathrm{A} / \mathrm{A}$ & 1.792 & 0.214 & $6.000(0.354-101.568)$ \\
\hline & & $A / G$ & 1.727 & $.001^{* *}$ & $5.625(2.004-15.792)$ \\
\hline & & $\mathrm{G} / \mathrm{G}$ & 1.438 & $.001^{* *}$ & $4.211(1.817-9.758)$ \\
\hline & $\mathrm{AMH}(\mathrm{ng} / \mathrm{ml})$ & $\mathrm{A} / \mathrm{A}$ & 101.39 & 0.993 & \\
\hline & & $A / G$ & 0.599 & $0.004^{* *}$ & $1.821(1.215-2.730)$ \\
\hline & & $\mathrm{G} / \mathrm{G}$ & 0.526 & $<0.0001^{* * *}$ & $1.693(1.285-2.231)$ \\
\hline \multirow[t]{12}{*}{ rs17782313 } & hirsutism & $\mathrm{C} / \mathrm{C}$ & 21.896 & 0.999 & \\
\hline & & $C / T$ & 2.119 & $0.008^{* *}$ & $8.32(1.717-40.311)$ \\
\hline & & $T / T$ & 3.162 & $<0.0001^{* * *}$ & 23.625 (5.126-108.889) \\
\hline & loss of hair & $\mathrm{C} / \mathrm{C}$ & 2.708 & 0.089 & $15(0.663-339.548)$ \\
\hline & & $C / T$ & 1.646 & $0.003^{* *}$ & $5.185(1.747-15.386)$ \\
\hline & & $\mathrm{T} / \mathrm{T}$ & 1.212 & $0.009^{* *}$ & $3.362(1.361-8.303)$ \\
\hline & $\mathrm{HA}$ & $\mathrm{C} / \mathrm{C}$ & 1.609 & 0.278 & $5.000(0.273-91.518)$ \\
\hline & & $C / T$ & 1.776 & $.001^{* *}$ & $5.907(2.116-16.492)$ \\
\hline & & $\mathrm{T} / \mathrm{T}$ & 1.412 & $.001^{* *}$ & 4.103 (1.768-9.518) \\
\hline & $\mathrm{AMH}(\mathrm{ng} / \mathrm{ml})$ & $\mathrm{C} / \mathrm{C}$ & 101.26 & 0.993 & \\
\hline & & $\mathrm{C} / \mathrm{T}$ & 0.598 & $0.003^{* *}$ & $1.818(1.227-2.694)$ \\
\hline & & $\mathrm{T} / \mathrm{T}$ & 0.536 & $<0.0001^{* * *}$ & $1.71(1.293-2.261)$ \\
\hline
\end{tabular}


on PCOS opposed our findings because they found no association between MC4R SNPs (rs12970134 and rs17782313) and BMI [36], although the mean of BMI in the recruited patients $>30 \mathrm{~kg} / \mathrm{m}^{2}$. This variation could be attributed to ethnic differences and environmental stimuli.

Our study also showed that A and C alleles in rs12970134 and rs17782313, respectively, are the risk alleles that are associated with high BMI in PCOS women in Saudi Arabia. These alleles were anticipated as global risk alleles for MC4R variants in obesity [26, 27]. Recently, the rs17782313 variant was detected to be associated with moderate obesity in the Saudi population [37]. To our knowledge, we are the first group to predict the risk alleles in these variants that are associated with PCOS symptoms. Thus, the G and T alleles in rs12970134 and rs17782313, respectively, in homozygous or heterozygous states among non-obese patients are associated with PCOS symptoms including hirsutism, loss of hair, HA and high AMH. Previously, Mahmoudi et al. studied the association between six $M C 4 R$ variants and female pattern hair loss but in non-PCOS subjects; none of the genotyped variants displayed any significant association [38]. Lean women with PCOS have different phenotypic and clinical characteristics than obese and thus, till now, there is debate on their characteristics [39]. Therefore, the characterization of different sub-populations is of great importance to manipulate specific management and treatment.

\section{Conclusion}

In conclusion, this genetic study reveals that $M C 4 R$ variants (rs12970134 and rs17782313) with genotypes A/A and $\mathrm{C} / \mathrm{C}$, respectively, were highly associated with obesity in PCOS. Different genotypes of these variants were associated with clinical characteristics in non-obese PCOS women such as hirsutism, loss of hair, HA or high AMH. Therefore, high BMI $\left(>30 \mathrm{~kg} / \mathrm{m}^{2}\right)$ is the major cause of PCOS in Saudi Arabia. In addition, poor prognosis in the lean PCOS group could be associated with reverse genotypes.

\section{Abbreviations}

AES: Androgen Excess Society; AMH: Anti-Müllerian hormone; BMI: Body mass index; FSH: Follicle stimulating hormone; GWAS: Genome-wide association studies; HA: Hyperandrogenism; LH: Luteinizing hormone; MC4R: Melanocortin 4 receptor; NIH: National Institutes of Health; OA: Oligo/ anovulation; OR: Odds ratio; PCOM: Polycystic ovarian morphology; PCOS: Polycystic ovary syndrome; SNP: Single nucleotide polymorphism

\footnotetext{
Acknowledgements

The authors would like to show great appreciation to Ms. Nusaybah Abdullah Bamuhair, Lecturer in KAU for her contribution to the project, Mrs. Angham Nawar, Radiology and Imaging technician at CIPM, and Mrs. Jawaher Alsaedi nurse at CIPM for collecting the blood samples from the subjects. In addition, the authors thank Mr. Salah Barnawi, Statistics Department, King Fahad Medical Research Centre, King Abdulaziz University, Saudi Arabia for his valuable advice in statistical methods.
}

\section{Disclosure summary}

The authors have nothing to disclose.

\section{Authors' contributions}

SB conceptualized the study. OSB Obstetrician and Gynaecologist who diagnosed the patients. $A A B, N F$ and $A D$ performed experiments and analysed data. AAB, AGC and SB wrote the manuscript. SB corrected the final version of the manuscript. All authors have read and approved the final manuscript.

\section{Funding}

This study was funded by the Centre of Innovation in Personalized Medicine (CIPM), King Abdulaziz University, Jeddah, Saudi Arabia. CIPM has no role in the design of the study and collection, analysis, and interpretation of data and in writing the manuscript.

\section{Availability of data and materials \\ Not applicable}

\section{Ethics approval and consent to participate}

The study was approved by the Biomedical Ethics Unit, Faculty of Medicine, KAU (approval number: 407-15) and written informed consent was obtained from participants prior to sample collection.

\section{Consent for publication}

Not applicable

\section{Competing interests}

The authors declare that they have no competing interests.

\section{Author details}

${ }^{1}$ Biochemistry Department, King Abdulaziz University, P.O. Box 80218, Abdullah Sulayman St., Jeddah 21589, Saudi Arabia. ${ }^{2}$ Centre of Innovation in Personalized Medicine, King Abdulaziz University, P.O. Box 80216, Jeddah, Saudi Arabia. ${ }^{3}$ Department of Obstetrics and Gynaecology, Faculty of Medicine, King Abdulaziz University, P.O. Box 80205, Jeddah, Saudi Arabia.

Received: 21 December 2018 Accepted: 12 August 2019

Published online: 20 August 2019

\section{References}

1. Sirmans SM, Pate KA. Epidemiology, diagnosis, and management of polycystic ovary syndrome. Clin Epidemiol. 2013;6:1-13.

2. Dumesic DA, Oberfield SE, Stener-Victorin E, Marshall JC, Laven JS, Legro RS. Scientific statement on the diagnostic criteria, epidemiology, pathophysiology, and molecular genetics of polycystic ovary syndrome. Endocr Rev. 2015;36(5):487-525.

3. Sudo S, Kudo M, Wada S, Sato O, Hsueh AJ, Fujimoto S. Genetic and functional analyses of polymorphisms in the human FSH receptor gene. Mol Hum Reprod. 2002;8(10):893-9.

4. March WA, Moore VM, Willson KJ, Phillips DI, Norman RJ, Davies MJ. The prevalence of polycystic ovary syndrome in a community sample assessed under contrasting diagnostic criteria. Hum Reprod. 2010;25(2):544-51.

5. Mortada R, Williams T. Metabolic syndrome: polycystic ovary syndrome. FP Essent. 2015;435:30-42.

6. Ding T, Hardiman PJ, Petersen I, Wang FF, Qu F, Baio G. The prevalence of polycystic ovary syndrome in reproductive-aged women of different ethnicity: a systematic review and meta-analysis. Oncotarget. 2017;8(56):96351-8.

7. Rotterdam EA-SPCWG. Revised 2003 consensus on diagnostic criteria and long-term health risks related to polycystic ovary syndrome. Fertil Steril. 2004;81(1):19-25.

8. Balen AH, Laven JS, Tan SL, Dewailly D. Ultrasound assessment of the polycystic ovary: international consensus definitions. Hum Reprod Update. 2003;9(6):505-14.

9. Wiweko B, Maidarti M, Priangga MD, Shafira N, Fernando D, Sumapraja K, Natadisastra M, Hestiantoro A. Anti-mullerian hormone as a diagnostic and prognostic tool for PCOS patients. J Assist Reprod Genet. 2014;31(10):1311-6.

10. Ketefian A, Goodarzi M. Polycystic ovary syndrome. In: Murray MF, Babyatsky MW, Giovanni MA, Alkuraya FS, Stewart DR, editors. Clinical Genomics: Practical Applications in Adult Patient Care. NY: McGraw-Hill Education; 2014. 
11. Fauser BC, Tarlatzis BC, Rebar RW, Legro RS, Balen AH, Lobo R, Carmina E, Chang J, Yildiz BO, Laven JS, et al. Consensus on women's health aspects of polycystic ovary syndrome (PCOS): the Amsterdam ESHRE/ASRM-sponsored 3rd PCOS consensus workshop group. Fertil Steril. 2012;97(1):28-38 e25.

12. Corbett $S$, Morin-Papunen $L$. The polycystic ovary syndrome and recent human evolution. Mol Cell Endocrinol. 2013:373(1-2):39-50.

13. Al-Ruhaily AD, Malabu UH, Sulimani RA. Hirsutism in Saudi females of reproductive age: a hospital-based study. Ann Saudi Med. 2008;28(1):28-32.

14. Kiddy DS, Hamilton-Fairley D, Bush A, Short F, Anyaoku V, Reed MJ, Franks S. Improvement in endocrine and ovarian function during dietary treatment of obese women with polycystic ovary syndrome. Clin Endocrinol. 1992; 36(1):105-11.

15. Knochenhauer ES, Key TJ, Kahsar-Miller M, Waggoner W, Boots LR, Azziz R. Prevalence of the polycystic ovary syndrome in unselected black and white women of the southeastern United States: a prospective study. J Clin Endocrinol Metab. 1998;83(9):3078-82.

16. Yildiz BO, Knochenhauer ES, Azziz R. Impact of obesity on the risk for polycystic ovary syndrome. J Clin Endocrinol Metab. 2008;93(1):162-8.

17. Dunaif A. Insulin resistance and the polycystic ovary syndrome: mechanism and implications for pathogenesis. Endocr Rev. 1997;18(6):774-800.

18. Goodarzi MO, Azziz R. Diagnosis, epidemiology, and genetics of the polycystic ovary syndrome. Best Pract Res Clin Endocrinol Metab. 2006;20(2):193-205.

19. Herbert A, Gerry NP, McQueen MB, Heid IM, Pfeufer A, Illig T, Wichmann HE, Meitinger T, Hunter D, Hu FB, et al. A common genetic variant is associated with adult and childhood obesity. Science. 2006;312(5771):279-83.

20. McCarthy MI, Zeggini E. Genome-wide association studies in type 2 diabetes. Curr Diab Rep. 2009;9(2):164-71.

21. Renstrom F, Payne F, Nordstrom A, Brito EC, Rolandsson O, Hallmans G, Barroso I, Nordstrom P, Franks PW, Consortium G. Replication and extension of genome-wide association study results for obesity in 4923 adults from northern Sweden. Hum Mol Genet. 2009;18(8):1489-96.

22. Loos RJ, Lindgren CM, Li S, Wheeler E, Zhao JH, Prokopenko I, Inouye M, Freathy RM, Attwood AP, Beckmann JS, et al. Common variants near MC4R are associated with fat mass, weight and risk of obesity. Nat Genet. 2008; 40(6):768-75.

23. Scuteri A, Sanna S, Chen WM, Uda M, Albai G, Strait J, Najjar S, Nagaraja R, Orru M, Usala G, et al. Genome-wide association scan shows genetic variants in the FTO gene are associated with obesity-related traits. PLoS Genet. 2007;3(7):e115.

24. Yuan $H$, Zhu G, Wang F, Wang X, Guo H, Shen M. Interaction between common variants of FTO and MC4R is associated with risk of PCOS. Reprod Biol Endocrinol. 2015;13:55.

25. Balthasar N, Dalgaard LT, Lee CE, Yu J, Funahashi H, Williams T, Ferreira M, Tang $\checkmark$, McGovern RA, Kenny CD. Divergence of melanocortin pathways in the control of food intake and energy expenditure. Cell. 2005;123(3):493-505.

26. Chambers JC, Elliott P, Zabaneh D, Zhang W, Li Y, Froguel P, Balding D, Scott J, Kooner JS. Common genetic variation near MC4R is associated with waist circumference and insulin resistance. Nat Genet. 2008;40(6):716-8.

27. Thorleifsson G, Walters GB, Gudbjartsson DF, Steinthorsdottir V, Sulem P, Helgadottir A, Styrkarsdottir U, Gretarsdottir S, Thorlacius S, Jonsdottir I, et al. Genome-wide association yields new sequence variants at seven loci that associate with measures of obesity. Nat Genet. 2009;41(1):18-24.

28. Albuquerque D, Nobrega C, Rodriguez-Lopez R, Manco L. Association study of common polymorphisms in MSRA, TFAP2B, MC4R, NRXN3, PPARGC1A, TMEM18, SEC16B, HOXB5 and OLFM4 genes with obesity-related traits among Portuguese children. J Hum Genet. 2014;59(6):307-13.

29. Bazzi MD, Nasr FA, Alanazi MS, Alamri A, Turjoman AA, Moustafa AS, Alfadda AA, Pathan AA, Parine NR. Association between FTO, MC4R, SLC30A8, and KCNQ1 gene variants and type 2 diabetes in Saudi population. Genet Mol Res. 2014;13(4):10194-203.

30. Xi B, Chandak GR, Shen Y, Wang Q, Zhou D. Association between common polymorphism near the MC4R gene and obesity risk: a systematic review and meta-analysis. PLoS One. 2012;7(9):e45731.

31. Scherag A, Jarick I, Grothe J, Biebermann H, Scherag S, Volckmar AL, Vogel Cl, Greene B, Hebebrand J, Hinney A. Investigation of a genome wide association signal for obesity: synthetic association and haplotype analyses at the melanocortin 4 receptor gene locus. PLoS One. 2010;5(11):e13967.

32. Karrer-Voegeli S, Rey F, Reymond MJ, Meuwly JY, Gaillard RC, Gomez F. Androgen dependence of hirsutism, acne, and alopecia in women: retrospective analysis of 228 patients investigated for hyperandrogenism. Medicine (Baltimore). 2009;88(1):32-45.
33. Yildiz BO. Diagnosis of hyperandrogenism: clinical criteria. Best Pract Res Clin Endocrinol Metab. 2006;20(2):167-76.

34. Ewens KG, Jones MR, Ankener W, Stewart DR, Urbanek M, Dunaif A, Legro RS, Chua A, Azziz R, Spielman RS. FTO and MC4R gene variants are associated with obesity in polycystic ovary syndrome. PLoS One. 2011;6(1):e16390.

35. Louwers Y, Rayner NW, Herrera BM, Stolk L, Groves CJ, Barber TM, Uitterlinden AG, Franks S, Laven JS, McCarthy MI. BMI-associated alleles do not constitute risk alleles for polycystic ovary syndrome independently of BMl: a case-control study. PLoS One. 2014;9(1):e87335.

36. Tan S, Scherag A, Janssen OE, Hahn S, Lahner H, Dietz T, Scherag S, Grallert $\mathrm{H}$, Vogel $\mathrm{Cl}$, Kimmig $\mathrm{R}$, et al. Large effects on body mass index and insulin resistance of fat mass and obesity associated gene (FTO) variants in patients with polycystic ovary syndrome (PCOS). BMC Med Genet. 2010;11:12.

37. Cyrus C, Ismail MH, Chathoth S, Vatte C, Hasen M, Al Ali A. Analysis of the impact of common polymorphisms of the FTO and MC4R genes with the risk of severe obesity in Saudi Arabian population. Genet Test Mol Biomarkers. 2018;22(3):170-7.

38. Mahmoudi H, Redler S, Birch P, Drichel D, Dobson K, Tazi-Ahnini R, Tessmann P, Giehl KA, Kruse R, Lutz G, et al. Selected variants of the melanocortin 4 receptor gene (MC4R) do not confer susceptibility to female pattern hair loss. Arch Dermatol Res. 2013;305(3):249-53.

39. Goyal M, Dawood AS. Debates regarding lean patients with polycystic ovary syndrome: a narrative review. J Hum Reprod Sci. 2017;10(3):154-61.

\section{Publisher's Note}

Springer Nature remains neutral with regard to jurisdictional claims in published maps and institutional affiliations.

Ready to submit your research? Choose BMC and benefit from:

- fast, convenient online submission

- thorough peer review by experienced researchers in your field

- rapid publication on acceptance

- support for research data, including large and complex data types

- gold Open Access which fosters wider collaboration and increased citations

- maximum visibility for your research: over $100 \mathrm{M}$ website views per year

At BMC, research is always in progress.

Learn more biomedcentral.com/submissions 